\title{
EFEITO DE ANTIOXIDANTES NA PREVENÇÃO DE ESCURECIMENTO ENZIMÁTICO DE BATATA-DOCE (IPOMOEA BATATAS) E INHAME (DIOSCOREA SPP)
}

\author{
EFFECT OF ANTIOXIDANTS IN THE PREVENTION OF \\ ENZYMATIC BROWNING IN SWEET POTATO (IPOMOEA BATATAS) AND \\ YAM (DIOSCOREA SPP)
}

\author{
Luciana Cristina Brigatto Fontes ${ }^{1}$, Thaís Cristina Sivi², Kazumi Kawasaki Ramos ${ }^{3}$, \\ Fernanda Paula Collares Queiroz ${ }^{4}$
}

1 Universidade Estadual de Campinas (UNICAMP). Faculdade de Engenharia de Alimentos. Departamento de Tecnologia de Alimentos. Rua: Monteiro Lobato $\mathrm{n}^{\circ} 80$, Caixa Postal: 6121, Cep: 13083-862, Campinas - SP, Brasil. E-mail: 1cbfonte@ gmail.com

2 UNICAMP. Faculdade de Engenharia de Alimentos. Departamento de Tecnologia de Alimentos. E-mail: thaissivi@gmail.com

3 UNICAMP. Faculdade de Engenharia de Alimentos. Departamento de Tecnologia de Alimentos. E-mail: kazumiramos@gmail.com

4 UNICAMP. Faculdade de Engenharia Química. Cidade Universitária "Zeferino Vaz" - Caixa Postal 6066 - CEP 13083-970 - Campinas - SP, Brasil.

E-mail: collares.queiroz@gmail.com

Recebido para publicação em: 20/07/2007

Aceito para publicação em: 01/12/2009

\section{RESUMO}

O objetivo desta pesquisa foi avaliar o efeito de diferentes antioxidantes - ácido ascórbico, ácido cítrico, ácido oxálico e metabissulfito de sódio - na redução do escurecimento enzimático de batata-doce e inhame. Os tubérculos foram lavados, descascados, fatiados e imersos nas soluções antioxidantes. Foram realizadas análises para caracterização da matéria-prima e foi determinado em colorímetro o índice de escurecimento (IE). As batatas-doces controle, no terceiro dia, apresentaram IE 1,90 vezes superior em relação ao tratamento com solução de metabissulfito de sódio $2 \%$. O tratamento de metabissulfito de sódio (2\%) foi o único tratamento que não apresentou diferença significativa no decorrer do tempo de estocagem para batata-doce. Os inhames controle, no terceiro dia, apresentaram IE 4,29 vezes superior em relação ao tratamento com solução de metabissulfito de sódio $1 \%$. Os tratamentos metabissulfito de sódio (1 e $2 \%$ ) foram os únicos tratamentos que não apresentaram diferenças significativas no decorrer do tempo de estocagem para o inhame. $\mathrm{O}$ antioxidante de menor eficiência no processo foi $\mathrm{o}$ ácido oxálico $(0,01$ e $0,1 \%)$, e o de maior eficiência foi o metabissulfito de sódio $1 \%$ para inhame e $2 \%$ para batata-doce.

Palavras chaves: Tuberosas. Oxidação e cor. 


\begin{abstract}
The objective of this study was to evaluate the effect of different antioxidants: ascorbic acid, citric acid, oxalic acid and sodium metabisulphite to reduction the enzymatic browning of sweet potato and yam. The tubers were washed, peeled, sliced and immersed in solution antioxidants. Analyses were carried out to characterize the raw material and the browning index (BI) was determined daily using the colorimeter. On the third day, the control sweet potatoes showed a BI 1.90 times higher than those treated with the $2 \%$ sodium metabisulphite solution. The treatment with sodium metabisulphite $(2 \%)$ was the only one that did not present a significant difference during the storage period of sweet potato. On the third day, the control yams showed a BI 4.29 times higher than those treated with the $1 \%$ sodium metabisulphite solution. The treatments with sodium metabisulphite (1 and 2\%) were the only ones that did not present significant differences during the storage period for yam. The antioxidant with least efficiency in this process was oxalic acid $(0.01$ and $0.1 \%)$ and that with the greatest efficiency to yam was sodium metabisulphite $1 \%$ and to yam $2 \%$.
\end{abstract}

Keywords: Tuberous. Oxidation and color.

\section{INTRODUÇÃO}

O escurecimento de frutas e de certos vegetais é iniciado através da degradação oxidativa dos compostos fenólicos pela atuação de duas enzimas: a polifenoloxidase e a peroxidase (TOMÁS-BARBERÁN; ESPÍN, 2001). O produto final da oxidação é a quinona, que rapidamente se condensa, formando pigmentos escuros insolúveis, denominados melanina, ou reage não enzimaticamente com outros compostos fenólicos, aminoácidos e proteínas, formando também melanina (LUPETTI et al., 2005).

A polifenoloxidase atua principalmente após a ocorrência de danos mecânicos, cortes ou outros tipos de injúrias à célula. A célula injuriada tem, por sua vez, as paredes e membranas corrompidas, comprometendo a separação física entre as enzimas (localizadas nos plastídeos) e os substratos fenólicos (presentes nos vacúolos), favorecendo, assim, a reação de escurecimento (LEE, 2000; MARSHALL et al., 2000; MARTINEZ; WHITAKER, 1995).

O mecanismo de ação detalhado da polifenoloxidase foi descrito por BELITZ; GROSCH (1997). No centro ativo da enzima existem dois íons $\mathrm{Cu}+$, cujos campos de ligação contêm dois resíduos de histidina cada um. Seguindo mecanismo ordenado, a enzima liga primeiro o oxigênio e depois o monofenol. Mudança de valência dos íons cobre provoca a formação de complexo enzima-substrato, no qual a ligação $\mathrm{O}$ - O fica tão polarizada que ocorre a hidroxilação, seguida da formação de um o-difenol. A oxidação do o-difenol a o-quinona termina o ciclo. As quinonas são compostos amarelados, instáveis e reativos que podem reagir entre si, formando polímeros com alta massa molecular de cor escura, denominados melaninas; formar complexos com aminoácidos ou proteínas; e oxidar compostos com baixo potencial de oxidoredução (NICOLAS et al., 1994).

Do mesmo modo que as polifenoloxidases, as peroxidases têm atividade típica na reação de oxidação de compostos fenólicos em presença de peróxido de hidrogênio. Também são obtidas quinonas como produto, as quais são instáveis e após a oxidação não enzimática na presença de $\mathrm{O}_{2}$ polimerizam-se e formam as melaninas (CHITARRA, 2002).

As peroxidases contêm um grupo prostético heme (ferriprotoporfirina IX) e no processo catalítico oxidam de forma transitória o íon férrico a estados de valência mais alta. O peróxido pode ser o de hidrogênio ou peróxido orgânico, como metil ou etil peróxido de hidrogênio. Na reação que envolve a peroxidase, o doador de elétrons pode ser o ascorbato, as aminas e outros compostos orgânicos, tais como os fenóis (RICHARDSON; HYSLOP, 2000).

A reação de escurecimento em frutas, vegetais e bebidas é um dos principais problemas na indústria de alimentos. Estima-se que em torno de $50 \%$ da perda de frutas tropicais no mundo é devida à enzi- 
ma polifenoloxidase. A ação dessa enzima conduz à formação de pigmentos escuros, frequentemente acompanhados de mudanças indesejáveis na aparência e nas propriedades organolépticas do produto, resultando na diminuição da vida útil e do valor de mercado (ARAUJO, 2008).

A prevenção da oxidação em tecidos vegetais pode ser realizada por: (i) inativação térmica da enzima pelo uso do calor; (ii) exclusão ou remoção de um ou ambos os substratos (oxigênio, enzima e substrato); (iii) redução do $\mathrm{pH}$ em duas ou mais unidades abaixo do pH ótimo (6,0); (iv) adição de substâncias redutoras que inibam a ação da polifenoloxidase ou previnam a formação da melanina (como o ácido ascórbico ou ácido cítrico) (ARAUJO, 2008).

Os processos físicos de conservação de alimentos, como a desidratação, o armazenamento a baixas temperaturas e tratamentos térmicos, apesar de serem os mais adotados, possuem uma série de limitações. Alguns alimentos não podem passar por esses processos, pois podem alterar suas propriedades organolépticas, como sabor e odor (LUPETTI et al., 2005).

Os métodos químicos estão baseados em um sistema oxidante que necessita da presença de três compostos: enzima, oxigênio e substrato. Para evitar a oxidação, é necessário inativar a enzima ou eliminar o oxigênio. Entretanto, a inativação das enzimas é, algumas vezes, prejudicial, e a eliminação do oxigênio é difícil. Nesse caso, o único recurso possível é o uso de substâncias antioxidantes (FAGUNDES; AYUB, 2005).

O ácido ascórbico é reconhecido por sua ação redutora e contribuição nutricional (vitamina $\mathrm{C}$ ). Esse ácido e seus vários sais neutros são os principais antioxidantes para o uso em frutas e hortaliças e seus sucos, visando à prevenção do escurecimento e outras reações oxidativas (WILEY, 1994). Atua sequestrando o cobre, grupo prostético da polifenoloxidase, e reduzindo quinonas de volta a fenóis, antes de formarem pigmentos escuros (SAPERS; MILLER, 1998). O uso do ácido ascórbico como antioxidante, além de ser totalmente seguro para consumo humano, barato e bem aceito pelos consumidores, pode aumentar o teor de vitamina C (PRÉSTAMO; MANZANO, 1993).

O ácido cítrico é um dos principais ácidos orgânicos naturais em frutas, previne o escurecimento enzimático pela ação sobre polifenoloxidases e peroxidases. Também é utilizado para potencializar (ação sinergista) outros antioxidantes, como o ácido ascórbico (CHITARRA, 2002).

Alguns compostos antioxidantes naturais, como os ácidos cítrico e ascórbico, têm a capacidade de reduzir as quinonas formadas pela ação das oxidases, impedindo, dessa forma, a formação dos produtos escurecidos, além de poderem agir como inibidores das enzimas oxidativas, através do abaixamento do pH (BEZERRA et al., 2002).

O ácido oxálico é um antioxidante quelante, no entanto possui algumas limitações de utilização por ser um ácido muito forte. Esse ácido foi utilizado em maçãs, peras e bananas, visando à redução do escurecimento interno dos frutos, e mostrou-se eficiente (LUPETTI, 2005).

O sulfito ou agente sulfitante refere-se ao dióxido de enxofre gasoso ou aos sais de sódio, potássio e cálcio de sulfito hidrogênio (bissulfito), dissulfito (metabissulfito) ou íons de sulfito (MACHADO; TOLEDO, 2006). Os sulfitos são agentes multifuncionais, pois previnem o escurecimento enzimático e o não-enzimático, controlam o crescimento de microorganismos, agem como agentes branqueadores, antioxidantes ou redutores e realizam outras funções técnicas. Entretanto, os sulfitos apresentam algumas desvantagens: são corrosivos a equipamentos, podem reagir com alguns nutrientes e, ainda, prejudicar a textura e produzir sabor desagradável nos alimentos (JUNQUEIRA et al., 2009).

Nesta pesquisa, será avaliado o efeito de diferentes concentrações dos antioxidantes - ácido ascórbico, ácido cítrico, ácido oxálico e metabissulfito de sódio -na redução do escurecimento enzimático de batata-doce e inhame.

\section{MATERIAL E MÉTODOS}

\subsection{Matéria-prima}

A batata-doce (Ipomoea batatas) monalisa amarela e o inhame (Dioscorea spp) foram adquiridos no CEASA-Campinas. O hipoclorito de sódio, utilizado para higienização, foi da marca CHEMCO. Os antioxidantes utilizados foram: (i) ácido ascórbico (marca NUCLEAR), (ii) ácido cítrico (marca SYNTH), (iii) ácido oxálico (marca ECIBRA) e (iv) metabissulfito de sódio (marca SYNTH). 


\subsection{Preparo das fatias de batata-doce e inhame}

Os vegetais foram lavados em água corrente para a retirada de sujidades grosseiras oriundas do campo e higienizados por imersão em solução de hipoclorito de sódio na concentração de $0,2 \%$ durante 10 minutos. Posteriormente, os tubérculos foram descascados com auxílio de descascador manual de aço inoxidável e mantidos imersos em água filtrada até o momento do processamento. A seguir, foi iniciado o fatiamento, na espessura de $3 \mathrm{~mm}$, em Processador de Alimentos EL. Inox (marca SKYMSEN, modelo PAIE, Brasil). Essa espessura foi estipulada para que não houvesse a passagem de luz pela fatia, resultando em um dado errôneo registrado pelo colorímetro.

\subsection{Preparo das soluções antioxidantes}

As concentrações estudadas das soluções antioxidantes foram baseadas em estudos científicos e testes preliminares (LUPETTI et al., 2005; FAGUNDES; AYUB, 2005): (i) 1 e $2 \%$ de ácido ascórbico (AA), ácido cítrico (AC) e metabissulfito de sódio (MBS); (ii) 0,01 e 0,1\% de ácido oxálico (AO). As fatias foram imersas nas soluções antioxidantes na proporção 2:1 (solução: vegetal) durante 15 minutos e algumas fatias foram separadas para o tratamento controle. Posteriormente, as fatias foram retiradas das soluções e estocadas sobre placas de plexiglas à temperatura de $25^{\circ} \mathrm{C}$ por um período de três dias.

\subsection{Análises físicas e químicas da matéria} prima

Os vegetais foram avaliados separadamente, em triplicata, quanto ao teor de umidade, de acordo com o método ${ }^{\circ}$ 44-40 (AACC, 1995); proteína, pelo método de Kjeldahl no 46-11 (AACC, 1995); cinzas, de acordo com o método n ${ }^{\circ}$ 08-01 (AACC, 1995); lipídios, segundo método Soxhlet 02-01 (AACC, 1995); fibra bruta (NORMAS ANALÍTICAS DO INSTITUTO ADOLFO LUTZ, 1985) e carboidratos por diferença (incluindo as fibras).
A análise instrumental de cor foi realizada pelo método triestímulos do sistema CIELab, utilizando-se colorímetro, modelo Color Quest II, marca Hunter Lab com calibração: (i) ângulo de observação de $10^{\circ}$ e (ii) iluminante $\mathrm{D}_{65}$. Os parâmetros avaliados foram (L, a e b) e determinado o índice de escurecimento (IE) diariamente, em quadruplicata, no período de três dias, conforme Equações (1) e (2).

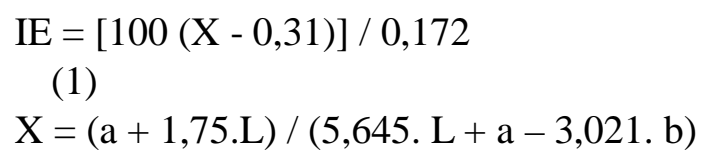

(2)

Onde: IE é o índice de escurecimento;

Lé a luminosidade do branco ao preto; a é o eixo de cromaticidade do verde (-) ao vermelho (+);

b é o eixo de cromaticidade do azul (-) ao amarelo (+).

\subsection{Análise estatística}

O programa estatístico SAS (Statistical Analysis System) foi utilizado na análise de variância pelo teste $\mathrm{F}$ e comparação de médias pelo Teste de Tukey $(5 \%)$.

\section{RESULTADOS E DISCUSSÃO}

\subsection{Análises físicas e químicas}

Os valores encontrados para composição centesimal (Tabela 1) são semelhantes aos relatados por SOARES et al. (2002) para batata-doce, e por LEONEL; CEREDA (2002) para inhame. As diferenças encontradas são decorrentes provavelmente da variedade, do solo e do clima.

\subsection{Análise instrumental de cor}


Tabela 1 - Médias e desvio padrão da composição centesimal de batata-doce e inhame.

(b.s.) $=$ base seca

\begin{tabular}{c|c|c}
\hline Determinações & Batata-doce & Inhame \\
\hline Umidade \% & $64,37 \pm 0,32$ & $64,00 \pm 0,28$ \\
\hline Proteína \% (b.s) & $6,47 \pm 0,02$ & $3,89 \pm 0,48$ \\
\hline Cinzas \% (b.s.) & $215 \pm 0,09$ & $2,29 \pm 0,07$ \\
\hline Lipídios \% (b.s.) & $0,44 \pm 0,01$ & $0,17 \pm 0,06$ \\
\hline Fibras \% (b.s.) & $2,57 \pm 0,09$ & $1,61 \pm 0,73$ \\
\hline Carboidratos \% (b.s.) & $26,57 \pm 0,10$ & $24,65 \pm 0,32$ \\
\hline
\end{tabular}

A composição centesimal da batata-doce assemelha-se à do inhame no teor de umidade e cinzas. Todavia, a batata-doce apresenta maior porcentagem de proteína, lipídios, fibras e carboidratos. apresentaram índice de escurecimento 1,90 vezes superior em relação ao tratamento com solução de MBS 2\%.

O tratamento MBS (2\%) foi o único tratamento que não apresentou diferença significativa no decorrer do tempo de estocagem e, portanto, é a opção mais eficiente para a inibição do escurecimento enzimático de batata-doce.

O uso de sulfito $(50 \mathrm{mg} / \mathrm{kg})$ em maçãs desidratadas apresentou efeito positivo contra o escurecimento, sendo que maiores concentrações apresentaram maior grau de brancura (CARDOSO et al., 2007).

\section{2 Índice de escurecimento da batata-doce}

No dia 0 , não ocorreram diferenças significativas entre os tratamentos realizados, no entanto o tratamento controle apresentou o maior índice de escurecimento $(35,99)$. No dia 1 , os tratamentos $\mathrm{AC} 1 \%$ e $\mathrm{AO} 0,01 \%$ não diferiram estatisticamente do tratamento controle, permanecendo com os maiores índices de escurecimento. No dia 2, o tratamento controle só diferiu estatisticamente dos tratamentos MBS 1 e $2 \%$. No dia 3, os tratamentos que apresentaram os maiores índices de escurecimento foram: controle, AO 0,01\%, AC $1 \%$ e $2 \%$ (Tabela 2).

Os tratamentos AA 1 e $2 \%$ e MBS 1 e $2 \%$ não apresentaram diferenças significativas em cada dia avaliado. No entanto, no dia 3 , os tratamentos AA $1 \%$ e MBS $1 \%$ apresentaram maiores índices de escurecimento.

Os tratamentos AC 1 e $2 \%$ apresentaram diferença significativa no índice de escurecimento no dia 1 de estocagem. O tratamento $\mathrm{AC} 1 \%$ apresentou maior índice de escurecimento nos dias 1 e 3.

Os tratamentos AO 0,01 e 0,1\% apresentaram diferença significativa apenas no dia 3 , e o tratamento AO 0,01\% apresentou maior índice de escurecimento.

As batatas-doces controle, no terceiro dia,
Tabela 2 - Índice de escurecimento de batata-doce durante o período de 3 dias

\begin{tabular}{c|c|c|c|c}
\hline Tratamentos & Dia 0 & Dia 1 & Dia 2 & Dia 3 \\
\hline Controle & $35,99 \pm 0,06^{\mathrm{aB}}$ & $49,87 \pm 3,61^{\mathrm{aAB}}$ & $46,81 \pm 6,12^{\mathrm{aAB}}$ & $53,76 \pm 0,39^{\mathrm{abA}}$ \\
\hline ÁA $1 \%$ & $22,79 \pm 0,58^{\mathrm{aB}}$ & $27,65 \pm 3,89^{\mathrm{cdB}}$ & $39,87 \pm 0,97^{\mathrm{aA}}$ & $37,56 \pm 1,36^{\mathrm{cdA}}$ \\
\hline ÁA $2 \%$ & $24,68 \pm 3,10^{\mathrm{aB}}$ & $37,76 \pm 0,17^{\mathrm{bcA}}$ & $35,43 \pm 0,28^{\mathrm{abA}}$ & $31,26 \pm 3,96^{\mathrm{cdAB}}$ \\
\hline AC $1 \%$ & $32,47 \pm 0,06^{\mathrm{aB}}$ & $43,31 \pm 1,83^{\mathrm{abA}}$ & $41,73 \pm 0,81^{\mathrm{aA}}$ & $41,90 \pm 0,64^{\mathrm{abcA}}$ \\
\hline AC $2 \%$ & $24,42 \pm 0,94^{\mathrm{aB}}$ & $30,34 \pm 4,68^{\mathrm{cdAB}}$ & $36,53 \pm 0,29^{\mathrm{abA}}$ & $40,69 \pm 1,82^{\mathrm{bcdA}}$ \\
\hline AO 0,01\% & $34,26 \pm 10,47^{\mathrm{aB}}$ & $46,47 \pm 2,22^{\mathrm{abA}}$ & $37,82 \pm 7,73^{\mathrm{aB}}$ & $54,05 \pm 2,59^{\mathrm{aA}}$ \\
\hline AO 0,1\% & $35,91 \pm 0,63^{\mathrm{aC}}$ & $41,74 \pm 1,48^{\mathrm{abAB}}$ & $44,83 \pm 1,65^{\mathrm{aA}}$ & $37,22 \pm 0,10^{\mathrm{cdBC}}$ \\
\hline MBS $1 \%$ & $21,91 \pm 1,10^{\mathrm{aB}}$ & $21,36 \pm 0,20^{\mathrm{dB}}$ & $22,95 \pm 3,56^{\mathrm{bB}}$ & $36,28 \pm 0,28^{\mathrm{cdA}}$ \\
\hline MBS $2 \%$ & $29,02 \pm 2,80^{\mathrm{aA}}$ & $27,77 \pm 0,06^{\mathrm{cdA}}$ & $23,21 \pm 1,27^{\mathrm{bA}}$ & $28,16 \pm 8,46^{\mathrm{dA}}$ \\
\hline
\end{tabular}

Médias seguidas de mesma letra minúscula na coluna e maiúscula na linha não diferem entre si ao nível de $5 \%$ de significância. $\mathrm{AA}=$ ácido ascórbico; $\mathrm{AC}=$ ácido cítrico; $\mathrm{AO}=$ ácido oxálico; MBS= metabissulfito de sódio.

\section{3 Índice de escurecimento de inhame}

No dia 0 , os tratamentos AA $1 \%$ e AO $0,1 \%$ apresentaram os menores índices de escurecimento, diferindo estatisticamente dos demais tratamentos. No dia 1 , os tratamentos controle e AO 0,01 e $0,1 \%$ apresentaram os maiores índices de escurecimento, diferindo estatisticamente dos demais tratamentos. No dia 2, o tratamento controle diferiu estatisticamente dos demais tratamentos, apresentando o maior índice de escurecimento; já os tratamentos MBS 1 
e $2 \%$ apresentaram os menores índices de escurecimento (Tabela 3 ).

Os tratamentos controle, AA $1 \%$, AC $1 \%$, AO $0,01 \%$ e $0,1 \%$ não apresentaram diferenças significativas no dia 3 , e os tratamentos MBS 1 e $2 \%$ continuaram apresentando os menores índices de escurecimento.

Os tratamentos AA 1 e $2 \%$ apresentaram diferenças significativas nos dias 2 e 3 de estocagem, com menor índice de escurecimento para o tratamento AA $2 \%$ no dia 3 .

Os tratamentos AC 1 e $2 \%$ apresentaram diferença significativa no índice de escurecimento nos dias 2 e 3 de estocagem. O tratamento AC 1\% apresentou maior índice de escurecimento no dia 3.

Os tratamentos AO 0,01 e $0,1 \%$ apresentaram diferença significativa apenas no dia 3 , e o tratamento AO 0,01\% apresentou maior índice de escurecimento.

Tabela 3 - Índice de escurecimento de inhame durante o período de 3 dias.

\begin{tabular}{c|c|c|c|c}
\hline Tratamentos & Dia 0 & Dia 1 & Dia 2 & Dia 3 \\
\hline Controle & $13,94 \pm 0,38^{\mathrm{aB}}$ & $21,06 \pm 1,83^{\mathrm{aB}}$ & $38,25 \pm 1,15^{\mathrm{aA}}$ & $44,17 \pm 5,03^{\mathrm{abA}}$ \\
\hline ÁA $1 \%$ & $9,51 \pm 0,11^{\mathrm{bD}}$ & $14,06 \pm 0,03^{\mathrm{bcC}}$ & $27,92 \pm 0,00^{\mathrm{dB}}$ & $37,56 \pm 1,60^{\mathrm{bcA}}$ \\
\hline ÁA $\%$ & $12,50 \pm 0,38^{\mathrm{abC}}$ & $12,96 \pm 0,00^{\mathrm{bcC}}$ & $35,04 \pm 0,20^{\mathrm{bA}}$ & $30,07 \pm 1,71^{\mathrm{cB}}$ \\
\hline AC $1 \%$ & $10,55 \pm 0,05^{\mathrm{abC}}$ & $13,49 \pm 0,61^{\mathrm{bcC}}$ & $23,27 \pm 1,65^{\mathrm{eB}}$ & $44,82 \pm 0,59^{\mathrm{abA}}$ \\
\hline AC $2 \%$ & $11,44 \pm 1,17^{\mathrm{abB}}$ & $12,88 \pm 3,63^{\mathrm{bcB}}$ & $18,84 \pm 0,62^{\mathrm{fB}}$ & $29,67 \pm 0,67^{\mathrm{cA}}$ \\
\hline AO 0,01\% & $13,16 \pm 0,05^{\mathrm{abD}}$ & $15,99 \pm 0,91^{\mathrm{abcC}}$ & $33,25 \pm 0,77^{\mathrm{bcB}}$ & $49,07 \pm 0,41^{\mathrm{aA}}$ \\
\hline AO 0,1\% & $9,58 \pm 0,66^{\mathrm{bB}}$ & $16,70 \pm 0,32^{\mathrm{abB}}$ & $30,69 \pm 0,34^{\mathrm{cdA}}$ & $37,66 \pm 4,67^{\mathrm{bcA}}$ \\
\hline MBS $1 \%$ & $13,83 \pm 2,74^{\mathrm{aA}}$ & $12,20 \pm 0,03^{\mathrm{bcA}}$ & $11,35 \pm 0,42^{\mathrm{gA}}$ & $10,28 \pm 1,10^{\mathrm{dA}}$ \\
\hline MBS $2 \%$ & $10,55 \pm 0,58^{\mathrm{abA}}$ & $10,77 \pm 0,16^{\mathrm{cA}}$ & $8,64 \pm 0,46^{\mathrm{gB}}$ & $10,66 \pm 0,09^{\mathrm{dA}}$ \\
\hline
\end{tabular}

Médias seguidas de mesma letra minúscula na coluna e maiúscula na linha não diferem entre si ao nível de $5 \%$ de significância. $\mathrm{AA}=$ ácido ascórbico; $\mathrm{AC}=$ ácido cítrico; $\mathrm{AO}=$ ácido oxálico; $\mathrm{MBS}=$ metabissulfito de sódio constituem a opção mais eficiente para a inibição do escurecimento enzimático de inhame.

Os antioxidantes apresentaram comportamento similar tanto para a batata-doce como para o inhame. $\mathrm{O}$ antioxidante de menor eficiência no processo foi o ácido oxálico $(0,01$ e $0,1 \%)$, e o melhor foi o metabissulfito de sódio ( 1 e $2 \%$ ). No entanto, para a batata-doce a solução de metabissulfito de sódio $2 \%$ foi a mais eficaz contra o escurecimento enzimático, e para o inhame foi a solução de metabissulfito de sódio $1 \%$.

\subsection{Aspecto visual da batata-doce e do}

Pelas Figuras 1 e 2 podem ser confirmados visualmente os resultados obtidos pelo acompanhamento instrumental da alteração de cor, constatando-se que a solução de metabissulfito de sódio $2 \%$ para a batata-doce e $1 \%$ para o inhame foram eficazes na prevenção do escurecimento enzimático após a estocagem a $25^{\circ} \mathrm{C}$ durante três dias.

A batata-doce apresentou coloração esbranquiçada e pontos amarronzados, e o inhame estava praticamente amarronzado e com presença de fungos no dia 3 de estocagem.

Os inhames controle, no dia 3, apresentaram índice de escurecimento 4,29 vezes superior em relação ao tratamento com solução de MBS $1 \%$ (Tabela 3). Para os tratamentos AA (1\%), AC (1\%) e AO $(0,01$ e $0,1 \%)$, não ocorreram diferenças significativas entre o índice de escurecimento no terceiro dia de estocagem.

Os tratamentos MBS (1 e 2\%) foram os únicos tratamentos que não apresentaram diferenças significativas no decorrer do tempo de estocagem, por isso 


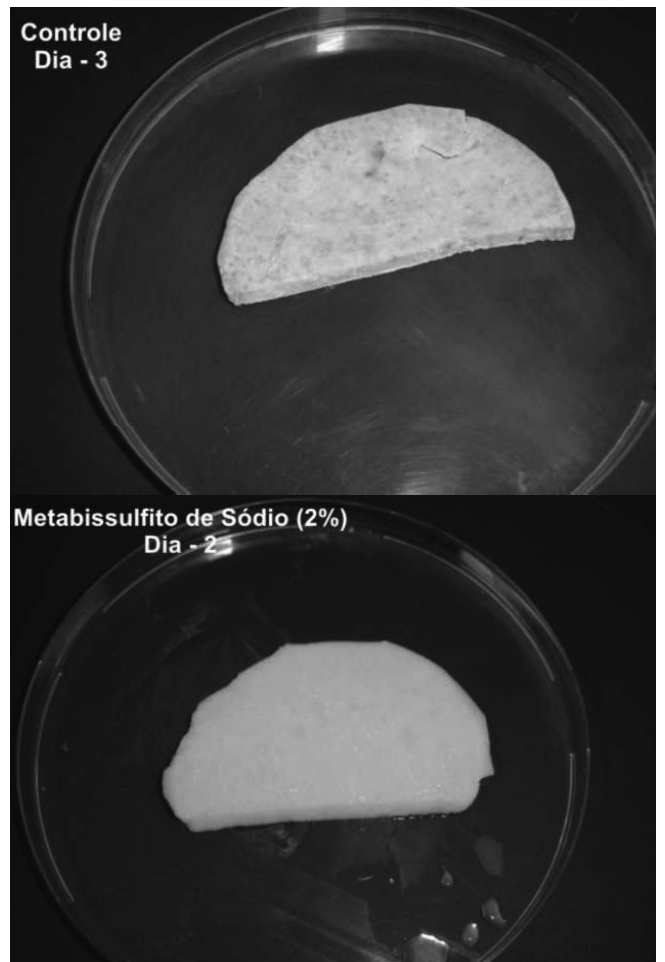

Figura 1 - Batata-doce controle e com solução de metabissulfito de sódio $2 \%$, no $3^{\circ}$ dia de estocagem.

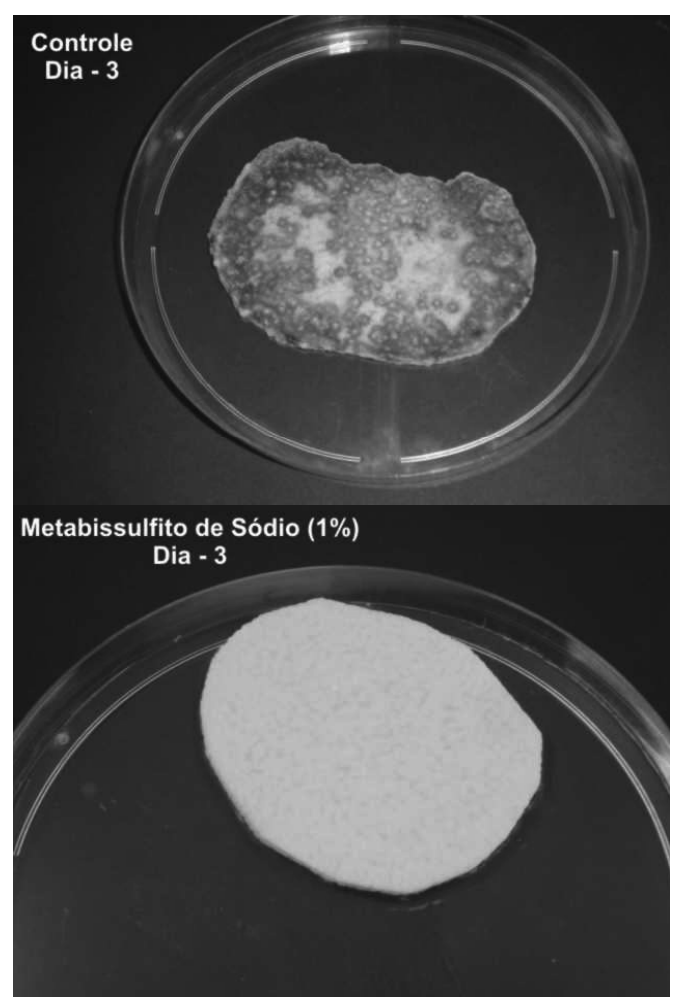

Figura 2 - Inhame controle e com solu-ção de metabissulfito de sódio $1 \%$, no $3^{\circ}$ dia de estocagem.

\section{CONCLUSÃO}

O processo de imersão de batata-doce em solução de metabissulfito de sódio $2 \%$ e de inhame em solução $1 \%$ do mesmo antioxidante constitui-se no método mais eficiente como tratamento preliminar para a inibição do escurecimento enzimático tanto nas condições e concentrações como no tipo de antioxidante deste estudo.

\section{AGRADECIMENTOS}

À CAPES, pela concessão da bolsa de doutorado; e à FAPESP, pelo auxílio à pesquisa.

\section{REFERÊNCIAS}

AACC. AMERICAN ASSOCIATION OF CEREAL CHEMISTS. Approved methods. 9 ed., Saint Paul: AACC, 1995.

ARAUJO, J.M.A. Química de alimentos: teoria e prática. 4. ed. Viçosa, SC: Ed. Universidade Federal de Viçosa, 2008. 596p.

BELITZ, H. D.; GROSCH, W. Química de los alimentos. 2. ed. Zaragoza: Acríbia, p. 119-120, 1997.

BEZERRA, V. S.; PEREIRA, R. G. F. A.; CARVALHO, V. D.; VILELA, E. R. Raízes de mandioca minimamente processadas: efeito do branqueamento na qualidade e na conservação. Ciência Agrotecnica, Lavras, v. 26, n. 3, p. 564-575, 2002.

CARDOSO, W. S.; PINHEIRO, F. A.; PATELLI, T.; PEREZ, R.; RAMOS, A. M. Determinação da concentração de sulfito para a manutenção da qualidade da cor em maçã desidratada. Revista Analytica, n.29, p.66, 2007.

CHITARRA, M. I. F. Processamento mínimo de frutas e hortaliças. Lavras: UFLA/FAEPE, 2002.

FAGUNDES, A. F.; AYUB, R. A. Caracterização físico-química de caquis cv. Fuyu submetidos à aplicação de agentes inibidores de escurecimento e armazenados a $0^{\circ} \mathrm{C}$. Acta Science Agronomy. Maringá, Paraná, v.27, n.3, p.403-408, 2005.

JUNQUEIRA, M. S.; SOARES, N. F. F.; REIS, R. C.; CARNEIRO, J. D. S.; BENÍCIO, R. T.; YOKOTA, R. C. Efeito de embalagens ativas no escurecimento enzimático de batatas (solanum tuberosum) fatiadas e minimamente processadas. Semina: Ciências Agrárias, Londrina, v. 30, n. 3, p. 613-618, 2009. 
LEE, C. Y. Enzymatic browning reaction. In: FRANCIS, F. J. Encyclopedia of Food Science and Technology. 2.ed. New York: John Wiley \& Sons, 2000. p. 208-218.

LEONEL, M.; CEREDA, M. P. Caracterização físico-química de algumas tuberosas amiláceas. Ciência e Tecnologia de Alimentos, v.22, n.1, p.65-69, 2002.

LUPETTI, K. O.; CARVAlHO, L. C.; MOURA, A. A.; FATIBELLO-FILHO, O. Análise de imagem em química analítica: empregando metodologias simples e didáticas para entender e prevenir o escurecimento de tecidos vegetais. Química Nova, v.28, n.3, p.548-554, 2005.

MACHADO, R. M. D.; TOLEDO, M. C. F. Sulfitos em Alimentos. Brazilian Journal Food Technology, v. 9, n. 4, p. 265-275, 2006.

MARSHALL M. R., KIM J.; WEI C. I. Enzymatic browning in fruits, vegetables and seafoods. Nutrition and Food Science Department, Alabama, 2000. Disponível em: <http:// www.fao.org/ag/Ags/agsi/ENZYME FINAL/Enzymatic\%20 Browning.html>.

MARTINEZ, M. V.; WHITAKER, J. R. The biochemistry and control of enzimatic browning. Trends in Food Science and Technology, Cambridge, v. 6, n. 6, p. 195-200, 1995.

NICOLAS, J. J.; RICHARD-FORGET, F. C.; GOUPY, P. M.; AMIOT, M. J.; AUBERT, S. Y. Enzymatic browning reaction in apple and apple products. Critical. Review. Food Science Nutrition, v. 34, p. 109-157, 1994.

NORMAS ANALÍTICAS DO INSTITUTO ADOLFO LUTZ. Métodos químicos e físicos para análise de alimentos. v.1, 533p., 1985.

PRESTAMO,G.; MANZANO, P. Peroxidases of selected fruits and vegetables and the possile use of ascorbic acid as na antioxidant. HortScience, v.28, n.1, p.48-50, 1993.

RICHARDSON, T.; HYSLOP, D. B. Enzimas. In: FENNEMA, O. R. (Dir.) Química de los alimentos. Zaragoza: Acríbia, 2000. p.501-503.

SAPERS, G. M.; MILLER, R. L. Browning inhibition in fresh-cut pears. Journal. Food Science, v. 63, n. 2, p. 342346, 1998.

SOARES, K. T.; MELO, A. S.; MATIAS, E. C. A cultura da batata doce (Ipomoea batatas (L.) Lam.). EMEPA-PB (Empresa Estadual de Pesquisa Agropecuária da Paraíba S. A.). João Pessoa: Documento 41, 2002, 26p.

TAYLOR, S. L. Sulfites in foods: uses, analytical methods, residues, fate, exposure, assessment, metabolism, toxicity, and hypersensitivity. Advances in Food Research, v. 30, p. 1-76, 1986.
TOMÁS-BARBERÁN, F. A.; ESPÍN, J. C. Phenolic compounds and related enzymes as determinants ofquality in fruits and vegetables. Journal Science Food Agriculture, n. 81, p. 853-879, 2001.

WILEY, R.C. Minimally processed refrigerated fruits and vegetables, London, CHAPMAN e HALL, 357 p., 1994. 